\title{
Evaluation of levetiracetam and valproic acid as monotherapy on quality of life in patients of generalized tonic clonic epilepsy
}

\author{
Sanjay K. Verma ${ }^{1}$, Suman Bala ${ }^{1 *}$, Yashpal Singh ${ }^{2}$, Saurabh Kohli ${ }^{1}$, Juhi Kalra ${ }^{1}$, \\ Dilip C. Dhasmana ${ }^{1}$, Taruna Sharma ${ }^{1}$
}

${ }^{1}$ Department of Pharmacology, ${ }^{2}$ Department of Neurology, Himalayan Institute of Medical Sciences, Dehradun, Uttarakhand, India

Received: 19 January 2018 Accepted: 05 March 2018

*Correspondence to:

Dr. Suman Bala,

Email: yashsuman2000

@gmail.com

Copyright: () the author(s), publisher and licensee Medip Academy. This is an openaccess article distributed under the terms of the Creative Commons Attribution NonCommercial License, which permits unrestricted noncommercial use, distribution, and reproduction in any medium, provided the original work is properly cited.

\begin{abstract}
Background: Quality of life plays an important role in patients of epilepsy and is the most neglected part during management. The antiepileptic drugs treatment results in seizure control but adversely affect the quality of life in patients.

Methods: An observational analytical study was conducted in the Department of pharmacology with Department of Neurology of Himalayan Institute of Medical Sciences, Dehradun over 12 months. 85 patients fulfilling the inclusion criteria with diagnosis of generalized tonic clonic seizures (GTCS) were enrolled and divided into two groups based on physicians discretion and followed up for 12 weeks. Patients were evaluated for quality of life by QOLIE-10 self administered questionnaire at 0 and 12 weeks, assessed for seizure control and drug related adverse effects.

Results: 85 patients were enrolled and divided into two treatment arms as per physician discretion, levetiracetam (41) and valproic acid group (44). Study drugs showed significant improvement in quality of life, levetiracetam showed mean change that was significantly greater than valproic acid $(\mathrm{p}=0.003)$ at 12 weeks. Patients who failed to achieve seizure control at 6 weeks were 17\% patients in levetiracetam and $20 \%$ in valproic acid group, reason being non-adherence which was $17 \%$ and $20 \%$ respectively. Adverse events recorded with Levetiracetam (10), most common being increased sleep and with valproic acid (18), with most common being increased sleep and weight gain.

Conclusions: Levetiracetam treatment resulted in better quality of life, with similar seizure control but decreased number of adverse effect then Valproic acid.
\end{abstract}

Keywords: Generalized tonic clonic seizure, Levetiracetam, Quality of life in epilepsy, QOLIE-10, Valproic acid

\section{INTRODUCTION}

Epilepsy is a common neurological disorder manifesting as recurrent neuronal discharges which may be limited to either one region (Focal) or diffusely spread over multiple regions (Generalized tonic clonic seizure (GTCS)) of brain and is characterized by loss of consciousness which is preceded by cry, foaming, twitching and vigorous jerky movements of limbs. Burden of epilepsy on society can be estimated based on its prevalence which is around 5-10 per 1000 population in different parts of world. The annual incidence of epilepsy in world population is 50/100000 and that in the Indian population is 27.3 per 100000 with prevalence of 5.59 per $1000 .^{1,2}$

For the most definitely diagnosed epilepsy, long-term treatment with anti-epileptic drugs (AEDs) is needed. ${ }^{3}$ Monotherapy is considered the gold standard in epilepsy and is preferred over polytherapy because of lesser risk of adverse events and drug interactions, the decreased cost of therapy and greater patient compliance. ${ }^{4}$

Adverse effects (diplopia, ataxia, sedation, cognitive issues, hyponatremia, headache, weight gain, dizziness, 
depression and paresthesia) occur at therapeutic doses in patients of epilepsy. Adverse effects of drugs also play a major role in ensuring quality of life in epilepsy patients along with the effects of epilepsy.

There are many disease specific tools for measurement of quality of life. These tools are in the form of questionnaire that can be administered to patients in the outpatient department. These tools help assess effect of both disease as well as treatment administered. Epilepsy specific tools are (Research and Development Corporation (RAND) 36Item Health Survey (SF-36), Quality of life in Epilepsy (QOLIE-89, QOLIE-31 and QOLIE-10)).

Efficacy of conventional AEDs has been well established but the area they lack is in the adverse effect caused by them. Newer AEDs though were started as adding on therapy to the conventional AEDs and have shown equal efficacy to conventional AEDs. Newer AEDs with their better safety profile hold an edge over the conventional AEDs. In this study we conceptualized comparing a broadspectrum AEDs from the older generation which is VPA with a drug of newer generation i.e. LEV. LEV has found its usage both approved as well as off label use in majority of types of seizures. Even after extensive search there was a lack of studies which compared VPA with LEV on efficacy, safety and quality of life both in India as well as world till date.

Hence this study was planned to compare valproic acid and levetiracetam as monotherapy for comparison of quality of life in patients of generalized tonic clonic seizures epilepsy.

\section{METHODS}

This was an observational analytical follow-up study in newly diagnosed, generalized tonic-clonic seizure (GTCS), patients. Minimum sample size which was required was 60 patients, with 30 patients in each group. Sample size was based on previous study which compared quality of life in epilepsy patients. ${ }^{5}$ Patients were included after taking a written informed consent. Patients were selected from out-patient department of Department of Neurology. Patients were followed up for a period of 12 weeks. Patient satisfying below mentioned inclusion criteria were included in the study: Patients diagnosed as GTCS, Patient of both sexes in the age group of 18-60 years, patients who have been stabilized on their respective drug dosage for more than 1.5 months or less than 4.5 months. Subjects excluded from the study were: Patients suffering from any other type of epilepsy, patients with progressive CNS disease and lesion, any uncontrolled comorbid condition, malignancy, hypersensitivity to the study drugs, participating in another study, subjects with deranged liver and renal functions, pregnant and lactating mothers, patients who have experienced acute onset of seizures related to drugs, alcohol, acute medical illness, patients leaving the study due to any reasons will be excluded from final analysis. Demographic profile and detailed history was obtained from each recruited patient; this included family history, educational status, age of onset of epilepsy, duration of disease, personal habits. A general physical examination was performed, and blood pressure was recorded EEG and CT heads was done. Blood test (haematological and biochemistry were done before starting of the treatment. Study subjects included in the study were divided into two groups of 30 each. The drugs were given to subjects on the basis of physician's discretion. The dose ranges of the two drugs at the start of the study were as follows for Levetiracetam (LEV) 500$2000 \mathrm{mg} /$ day and for Valproic acid (VPA) 300-1000mg/ day. After recruitment patients were assessed for the quality of life based on QOLIE-10 questionnaire and were also evaluated for efficacy and safety. ${ }^{6}$ Patients were evaluated at 0,6 and 12 weeks or earlier as the need arose. For efficacy and safety they were assessed on each visit with the help of patient maintained seizure diary, and self reporting of adverse drug reaction. Patients were evaluated at baseline ( 0 visit) and at 12 weeks for quality of life.

Assessment of quality of life in patients: The QOLIE-10 is a brief standardized instrument for screening patients with epilepsy about the impact of epilepsy on their lives. QOLIE-10 evaluates patients in three domains:

- Epilepsy effects which evaluated patients for memory, physical effects and mental effects.

- Mental health assessing for energy, depression and overall quality of life.

- Role functioning which evaluated patients for seizure worry, work, driving and social limits.

Scores for QOLIE- range from 1-5 for each question with minimum of 10 and maximum of 50. Higher the score poor is the expressed quality of life. Assessment of safety of treatment: A checklist of adverse drug reaction was prepared according to the most common adverse events occurring due to study drugs. Adverse drug reactions were recorded at every visit of the patient i.e. at monthly intervals. Seizure diary was used to record patient's experiences weekly and how their seizures improved or deteriorated, frequency of seizures, duration, post-ictal confusion seizure related injury.

Data management and analysis was done using Microsoft Excel 2007 and IBM SPSS version 20.0. Demographic data was presented as either frequency or Mean \pm SD. Intragroup comparison was done using Paired sample Student t-test and inter-group analysis was done using Unpaired Student t-test. Adverse events were interpreted and analyzed using descriptive statistics and chi-square test.

\section{RESULTS}

Total 100 patients were included after primary screening. Out of these 10 patients were less than 18 years, 5 were above 60 years of age, hence total no. of patients included for final analysis were 85 out of which 41 were in the LEV group and 44 in the VPA group. 
Table 1: Basic demographic profile of the patients included in the study.

\begin{tabular}{|c|c|c|}
\hline Demography & $\begin{array}{l}\text { Levetiracetam } \\
(\mathrm{N}=41)\end{array}$ & $\begin{array}{l}\text { Valproic } \\
\text { acid }(N=44)\end{array}$ \\
\hline $\begin{array}{l}\text { Age (years, } \\
\text { mean } \pm S D)\end{array}$ & $32.41 \pm 13.72$ & $25.91 \pm 11.347$ \\
\hline \multicolumn{3}{|l|}{ Sex } \\
\hline Male & $58.5(24)$ & $68.2(30)$ \\
\hline Female & $41.5(17)$ & $31.8(14)$ \\
\hline \multicolumn{3}{|l|}{ Religion } \\
\hline Hindu & $90.2(37)$ & $90.9(40)$ \\
\hline Muslim & $7.3(3)$ & $6.8(3)$ \\
\hline Christian & $2.4(1)$ & $2.3(1)$ \\
\hline \multicolumn{3}{|l|}{ Marital Status } \\
\hline Married & $63.4(26)$ & $54.5(24)$ \\
\hline Unmarried & $36.6(15)$ & $45.5(20)$ \\
\hline \multicolumn{3}{|l|}{ Educational Status } \\
\hline Below intermediate & $58.5(24)$ & $52.3(23)$ \\
\hline Above intermediate & $41.5(17)$ & $47.7(21)$ \\
\hline \multicolumn{3}{|l|}{ Place of residence } \\
\hline Rural & $34.1(14)$ & $61.4(27)$ \\
\hline Urban & & $38.6(17)$ \\
\hline \multicolumn{3}{|l|}{ Alcoholic } \\
\hline Alcoholic & $31.7(13)$ & $6.8(3)$ \\
\hline Non-alcoholic & $68.3(28)$ & $93.2(41)$ \\
\hline \multicolumn{3}{|l|}{ Smoking } \\
\hline Smoker & $31.7(13)$ & $6.8(3)$ \\
\hline Non-smoker & $68.3(28)$ & $93.2(41)$ \\
\hline \multicolumn{3}{|l|}{ Diet } \\
\hline Vegetarian & $48.8(20)$ & $45.5(20)$ \\
\hline Non-vegetarian & $51.2(21)$ & $54.5(24)$ \\
\hline
\end{tabular}

*Percentage (number of patients)

Table 2: Baseline pattern of epilepsy among both the study groups.

\begin{tabular}{|lll|}
\hline Parameters & LEV (41) & VPA (44) \\
\hline Family History & $9.8(4)$ & $4.5(2)$ \\
\hline Present & $90.2(37)$ & $95.5(42)$ \\
\hline Absent & $4.17 \pm 2.11$ & $4.39 \pm 2.52^{*}$ \\
\hline $\begin{array}{l}\text { Duration of Disease } \\
\text { (years, mean } \pm \text { SD) }\end{array}$ & $3.22 \pm 0.82$ & $3.25 \pm 1.01 *$ \\
\hline $\begin{array}{l}\text { Frequency of seizures } \\
\text { (per month, mean } \pm \text { SD) }\end{array}$ & 3.05 , & \\
\hline *p<0.05 was considered significant, student t-test
\end{tabular}

Table 5: Comparison of difference of QOLIE-10 scores based on place of origin (Intergroup comparison).

\begin{tabular}{|lllllll|}
\hline QOLIE-10 & Rural (54) & & & Urban (31) & \\
Score & LEV (27) & VPA (27) & p-value & LEV (14) & VPA (17) & p-value \\
\hline Epilepsy effect & $5.26 \pm 1.059$ & $2.89 \pm 1.81$ & $0.030^{*}$ & $5.29 \pm 1.44$ & $3.35 \pm 1.62$ & 0.663 \\
\hline Mental Effect & $5.37 \pm 1.149$ & $3.70 \pm 1.00$ & $0.011^{*}$ & $5.43 \pm 1.34$ & $2.88 \pm 1.41$ & 0.820 \\
\hline Role Function & $7.33 \pm 1.494$ & $5.07 \pm 2.06$ & 0.088 & $7.64 \pm 1.28$ & $4.24 \pm 2.31$ & $0.047^{*}$ \\
\hline Total Score & $17.96 \pm 1.629$ & $16.70 \pm 3.44$ & $0.002^{*}$ & $18.36 \pm 1.65$ & $15.76 \pm 2.31$ & 0.427 \\
\hline
\end{tabular}


Table 6: Comparison of difference of QOLIE-10 scores based on place of origin (Intra-group group comparison).

\begin{tabular}{|c|c|c|c|c|c|c|}
\hline \multirow{2}{*}{$\begin{array}{l}\text { QOLIE-10 } \\
\text { Score }\end{array}$} & \multicolumn{3}{|l|}{ LEV (41) } & \multicolumn{3}{|l|}{ VPA (44) } \\
\hline & Rural (27) & Urban (14) & p-value & Rural (27) & Urban (17) & p-value \\
\hline Epilepsy effect & $5.26 \pm 1.06$ & $5.29 \pm 1.44$ & 0.139 & $2.89 \pm 1.81$ & $3.35 \pm 1.62$ & 0.792 \\
\hline Mental Effect & $5.37 \pm 1.15$ & $5.43 \pm 1.34$ & 0.400 & $3.70 \pm 1.00$ & $2.88 \pm 1.41$ & 0.172 \\
\hline Role Function & $7.33 \pm 1.49$ & $7.64 \pm 1.28$ & 0.356 & $5.07 \pm 2.055$ & $4.24 \pm 2.31$ & 0.715 \\
\hline Total Score & $17.96 \pm 1.63$ & $18.36 \pm 1.65$ & 0.952 & $16.70 \pm 3.44$ & $15.76 \pm 2.31$ & 0.076 \\
\hline
\end{tabular}

Table 7: Comparison of difference of QOLIE-10 scores based on educational status (Intergroup comparison).

\begin{tabular}{|lllllll|}
\hline $\begin{array}{l}\text { QOLIE-10 } \\
\text { Score }\end{array}$ & \multicolumn{2}{l}{ Below Intermediate } & \multicolumn{3}{l|}{ Intermediate } \\
\hline Epilepsy effect & LEV (23) & VPA (24) & p-value & LEV (18) & VPA (20) & p-value \\
\hline Mental Effect & $5.35 \pm 1.22$ & $2.96 \pm 1.63$ & 0.284 & $5.67 \pm 1.03$ & $3.20 \pm 1.88$ & $0.019^{*}$ \\
\hline Role Function & $7.30 \pm 1.33$ & $3.42 \pm 1.67$ & 0.191 & $5.44 \pm 1.25$ & $3.35 \pm 2.03$ & 0.056 \\
\hline Total Score & $17.61 \pm 1.59$ & $16.42 \pm 2.51$ & 0.095 & $18.72 \pm 1.49$ & $16.25 \pm 3.67$ & $0.005^{*}$ \\
\hline
\end{tabular}

$* \mathrm{P}<0.05$, Independent sample t-test

Table 8: Comparison of difference of QOLIE-10 scores based on educational status (Between group comparison).

\begin{tabular}{|c|c|c|c|c|c|c|}
\hline \multirow[b]{2}{*}{ QOLIE-10 Score } & \multicolumn{2}{|l|}{ LEV (41) } & \multicolumn{2}{|c|}{ VPA (44) } & \multirow[b]{2}{*}{$\begin{array}{l}\text { Intermediate } \\
\text { (20) }\end{array}$} & \multirow[b]{2}{*}{ p-value } \\
\hline & $\begin{array}{l}\text { Below } \\
\text { Intermediate (23) }\end{array}$ & $\begin{array}{l}\text { Intermediate } \\
\text { (18) }\end{array}$ & p-value & $\begin{array}{l}\text { Below } \\
\text { Intermediate (24) }\end{array}$ & & \\
\hline Epilepsy effect & $4.96 \pm 1.22$ & $5.67 \pm 1.03$ & 0.517 & $2.96 \pm 1.63$ & $3.20 \pm 1.88$ & 0.387 \\
\hline Mental Effect & $5.35 \pm 1.19$ & $5.44 \pm 1.25$ & 0.755 & $3.42 \pm 1.67$ & $3.35 \pm 2.03$ & 0.304 \\
\hline Role Function & $7.30 \pm 1.33$ & $7.61 \pm 1.54$ & 0.921 & $4.79 \pm 1.69$ & $4.70 \pm 2.67$ & $0.012 *$ \\
\hline Total Score & $17.61 \pm 1.59$ & $18.72 \pm 1.49$ & 0.900 & $16.42 \pm 2.51$ & $16.25 \pm 3.67$ & 0.096 \\
\hline
\end{tabular}

$* \mathrm{P}<0.05$, Independent sample t-test

Table 9: Comparison of difference of QOLIE-10 scores based on gender (Intergroup comparison).

\begin{tabular}{|lllllll|}
\hline $\begin{array}{l}\text { QOLIE-10 } \\
\text { Score }\end{array}$ & Female (31) & & & Male (54) & & p-value \\
\hline Epilepsy effect & $4.63 \pm 1.09$ & $3.13 \pm 1.00$ & $0.033^{*}$ & $5.68 \pm 1.07$ & $3.03 \pm 1.61$ & 0.143 \\
\hline Mental Effect & $5.38 \pm 1.09$ & $2.53 \pm 1.41$ & 0.270 & $5.40 \pm 1.29$ & $3.83 \pm 1.87$ & 0.218 \\
\hline Role Function & $7.75 \pm 1.53$ & $4.40 \pm 2.59$ & 0.062 & $7.24 \pm 1.33$ & $4.93 \pm 1.94$ & 0.117 \\
\hline Total Score & $17.75 \pm 1.53$ & $15.27 \pm 2.87$ & 0.064 & $18.32 \pm 1.68$ & $16.90 \pm 3.05$ & $0.032^{*}$ \\
\hline PP $<0.05$, Indepen & & & & & & \\
\hline
\end{tabular}

Table 10: Comparison of difference of QOLIE-10 scores based on gender (Between group comparison).

\begin{tabular}{|lllllll|}
\hline \multirow{2}{*}{ QOLIE-10 Score } & LEV (41) & & & VPA (44) & Male (29) & p-value \\
\hline Epilepsy effect & Female (16) & Male (25) & p-value & Female (15) & Mal & 0.249 \\
\hline Mental Effect & $5.63 \pm 1.09$ & $5.68 \pm 1.07$ & 0.755 & $3.13 \pm 1.00$ & $3.03 \pm 1.61$ & 0.441 \\
\hline Role Function & $7.75 \pm 1.53$ & $5.40 \pm 1.29$ & 0.343 & $2.53 \pm 1.41$ & $3.83 \pm 1.87$ & 0.154 \\
\hline Total Score & $17.75 \pm 1.53$ & $18.32 \pm 1.68$ & 0.675 & $15.27 \pm 2.87$ & $16.90 \pm 3.05$ & 0.842 \\
\hline *P<0.05, Independent sample t-test & & & & & &
\end{tabular}

$* \mathrm{P}<0.05$, Independent sample t-test

Comparison of QOLIE-10 scores was done to see if the place of origin (Table 5 and 6), education status (Table 7 and 8), gender (Table 9 and 10) affected the quality of life in the two groups. Adherence was assessed at 6 and 12 weeks. $17.07 \%$ in LEV and 20\% in VPA group were found to be non adherent and these also suffered from seizure episode during the study period. Cost comparison was also done to see the total cost of monthly therapy which INR was $1051.46 \pm 216.93$ for LEV and $487.39 \pm 80.81$ for VPA. 
Table 11: Adverse events recorded during the course of study.

\begin{tabular}{|lll|}
\hline Adverse Events & LEV (10) & VPA (18)* \\
\hline Irritability & 2 & 1 \\
\hline Anorexia & 0 & 4 \\
\hline Increased Sleep & 5 & 6 \\
\hline Headache & 3 & 0 \\
\hline Weight Gain & 0 & 6 \\
\hline Loose Motion & 0 & 1 \\
\hline
\end{tabular}

*Chi-square test, Chi-value $0.2687, \mathrm{p}=0.604$

\section{DISCUSSION}

The penultimate goal for treatment of epilepsy is total freedom from seizures with minimum adverse events and an optimal quality of life. Adopting evaluation of the quality of life outcomes in the standard management plan along with traditional measures of assessment of seizure frequency and adverse effects needs to be encouraged. To address this objective, the present study compares the drugs levetiracetam and valproic acid on the basis of the quality of life in newly diagnosed patients with epilepsy.

General base line demographic details included in our studies were age, gender, and place of residence. Mean age of our population group was $32.41 \pm 13.72$ years and $25.91 \pm 11.35$ years in LEV and VPA groups respectively which was similar to a study where mean age of the patient was $31.8 \pm 11.0$ years. ${ }^{7}$ In present study male to female ratio was 63:37 which was slightly above from the same study where it was $57: 44 .{ }^{7}$ Rural urban divide among the patients included in the study groups was also seen which was 65.9 and 34.1 in LEV group and 61.4 and 38.6 in VPA group both groups were similar in this regard (Table 1).

The mean duration of illness was comparable in both the groups in present study. In LEV group it was $4.17 \pm 2.11$ years and in VPA it was $4.39 \pm 2.52$ years (Table 2) was lower than another study where the mean duration of the disease was found to be $6.62 \pm 4.21$ years. ${ }^{8}$ There were no episodes of status epilepticus recorded in both groups during the entire duration of this study as patients at the time of enrollment had already completed the titration phase. People with positive family history in both groups at $9.8 \%$ and $4.5 \%$ in LEV and VPA group respectively (Table 2). This result was similar as compared to another study. ${ }^{8}$

Epilepsy is both a medical diagnosis and a social label because people with epilepsy face many psychosocial challenges (anxiety, social stigma, difficulty in driving, unemployment) that can negatively impact the quality of life. Such growing recognition of the importance of the psychosocial effects of epilepsy has led to the need to quantify the quality of life in affected individuals. Hence, appropriate AEDs use, along with monitoring of adverse effects and assessment of the quality of life as an outcome measure is important in the management of epilepsy to achieve optimal seizure control. ${ }^{9}$ The quality of life in our study was assessed using standardized QOLIE-10 questionnaire as primary outcome measures. The questionnaire in QOLIE-10 assesses three aspects of the health of the epileptic patient; mental effects, epilepsy effects and role function. The score corresponding to each scale as well as the QOLIE-10 total score was calculated. ${ }^{10}$

Baseline QOLIE-10 score in LEV group at the beginning of the study was $34.41 \pm 1.45$ which decreased to $16.32 \pm 1.13$ at the end of 12 weeks (Table 3 ) showing a mean change of $18.10 \pm 1.63$ (Table 4) which was statistically significant $(\mathrm{p}<0.005)$. Scores in LEV group showed improvement by $36.2 \%$ from baseline. This result was supported by a study done by SS Hassan et al were the percentage change seen was $34.82 \% .{ }^{11}$ Subgroup analysis was also done in present study where different aspects of QOLIE-10 scores were compared which showed improvement in all spheres. The mean change in epilepsy effect $(5.25 \pm 1.18)$, mental effects $(5.39 \pm 1.20)$ and role function effects $(7.44 \pm 1.42)$ (Table 4). Role function showed the maximum improvement in the current study.

Baseline QOLIE-10 score in VPA group at the beginning of the study was $28.84 \pm 2.25$ which decreased to $12.50 \pm 1.64$ at the end of 12 weeks (Table 3) showing a mean change of $16.34 \pm 3.06$ (Table 4) which was statistically significant $(\mathrm{p}<0.05)$. Scores in VPA group showed improvement by $32.68 \%$ from the baseline. This was supported by two different studies. SANAD trial in which VPA was compared with LTG and TPM, where VPA showed improvement in the quality of life. ${ }^{12} \mathrm{~A}$ similar study was done in Spanish population comparing VPA with LTG showed improvement in the quality of life from baseline. ${ }^{5}$ Subgroup analysis in the present study showed improvement in all spheres. The mean change in epilepsy effect $(3.07 \pm 1.73)$, mental effects $(3.39 \pm 1.82)$ and role function effects $(4.75 \pm 2.17)$ (Table 4). Role function showed the maximum improvement.

We could not find studies where these two drugs were compared head to head even after an extensive literature search. Inter group comparison between the two groups showed statistically significant $(\mathrm{p}<0.05)$ difference in mean change in QOLIE-10 score i.e. $18.10 \pm 1.63$ for LEV and 16.34 \pm 3.06 (Table 4).

Freedom from seizure is an important parameter for measurement of the efficacy of treatment in epilepsy. How rapidly the seizure control is achieved as well as how good is seizure control, determines the length of treatment in epilepsy patients. Hence this was measured by patients reported seizure diary in our study. At the beginning of study mean seizure frequency per month was $3.22 \pm 0.82$ and 3.25 \pm 1.01 in LEV and VPA group respectively (Table 2 ). The frequency of seizure was less than other study done on epilepsy but this may be due to newer patients enrolled in our study. ${ }^{13}$ The patients who reported total seizure freedom at 6 weeks was $83 \%$ and $80 \%$ for LEV and VPA groups respectively and at 12 weeks both groups achieved 
complete seizure control. This is in accordance with another study where the freedom from seizure did not vary between older and newer AEDs. ${ }^{14}$

Adherence to medication plays an important role in chronic illnesses like epilepsy which can affect seizure recurrence which in turn affects the quality of life. In our study adherence was measured using pill counting. Adherence at 6 weeks was $83 \%$ and $80 \%$ in LEV and VPA group (not statistically significant $\mathrm{p}<0.05$ ) which may be due to more adverse effects as caused by VPA in comparison to LEV. Improved adherence improves quality of life this was supported by findings of another study. ${ }^{15}$ Adverse drug reaction is a major factor which will either motivate or demotivate patients to continue medication. Adverse effects result into decreased medication adherence which results into increased chances of seizure episodes and more the chances of seizure episodes hence poorer the quality of life. In the present study, the adverse events recorded were based on adverse effect check list during the entire period of study. A total number of adverse effects recorded in the study were 28, out of this $64.29 \%$ of adverse events occurred with VPA and $35.71 \%$ with LEV (Table 11). The adverse events were statistically significant between groups $(\mathrm{p}<0.05)$. As we did not find any head to head comparison of our study drugs we tried to correlate results with other studies which compared older versus newer AEDs. Our findings were not in accordance with other studies where it was inferred that both do not differ statistically in terms of adverse events (83). Adverse event in group LEV group were drowsiness (5), irritability (2\%) and headache (3). In VPA adverse events were anorexia (4), drowsiness (6), weight gain (6), irritability (1) and loose stools (1). The most common adverse effect in LEV group was drowsiness and in VPA group were anorexia and drowsiness (Table 11).

An important part of any study which compares two different drugs is to assess for the cost-benefit ratio in terms of efficacy and safety. In the present study, we determined that the average monthly cost of therapy for LEV was INR 1051.46 \pm 216.93 and for VPA was INR $487.39 \pm 80.81$. There was a significant difference in monthly cost of the two drugs, but this did not affect the patient's adherence as is expected with costly medication. As cost is an important factor which determines the continuation of medication by patients as stated by another study. ${ }^{16}$

Anti-epileptic treatment effectively controls seizure in patients of epilepsy. Both the drugs in our study effectively provided seizure control. Both the drugs in the study provide a positive influence on quality of life. Quality of life was not affected by gender. Seizure type and treatment administered has a positive influence on quality of life. There were no serious adverse events in this study in both groups.

The major limitation of our study was its short duration and only monotherapy was included. The results of the present study does not give information about the epilepsy pattern and its effect in patients less than 18 years and more than 60 years as well as in pregnant females or patients with co-morbid conditions. In spite of this it can pave path for further studies which can compare newer AEDs with older AEDs for comparison of quality of life in epileptic patients which is mostly overlooked.

Antiepileptic drugs are the mainstay of epilepsy treatment. In the present study it was seen that LEV as compared to VPA was equal in efficacy in terms of seizure control, lesser side effects and showed significant improvement in terms of quality of life in patients of GTCS.

\section{ACKNOWLEDGEMENTS}

Authors would like to thank Himalayan Institute of Medical Sciences, to have provided me the opportunity to conduct my research work. I acknowledge the contribution of my colleagues in the department and also indebted to all patients who consented to participate in this study.

Funding: No funding sources

Conflict of interest: None declared

Ethical approval: The study was approved by the Institutional Ethics Committee, approval number SRHU/HIMS/ETHICS/2017/111

\section{REFERENCES}

1. Tatum WO IV, Benbadis S, Vale FL. The neurosurgical treatment of epilepsy. Arch Fam Med. 2000;9:1142-6.

2. Banerjee TK, Ray BK, Das SK, Hazra A, Ghosal MK, Chaudhuri A, et al. A longitudinal study of epilepsy in Kolkata, India. Epilepsia. 2010;51:2384-91.

3. Nelson LP, Savelli-Castillo I. New antiepileptic agents. Pediatr Dent. 2004;26:58-62.

4. Kaminow L, Schimschock JR, Hammer AE, Vuong A. Lamotrigine monotherapy compared with carbamazepine, phenytoin, or valproate monotherapy in patients with epilepsy. Epilepsy Behav. 2003;4:65966.

5. Viteri C, Codina M, Cobaleda S, Lahuerta J, Barriga J, Morales MD. Quality of life in Spanish epilepsy patients on monotherapy with Lamotrigine or Valproic acid. Seizure. 2010;19:432-38.

6. Cramer JA, Perrine K, Devinsky O, Meador K. A brief questionnaire to screen for quality of life in epilepsy: the QOLIE-10. Epilepsia. 1996;37(6):577-82.

7. Norsa'adah B, Zainab J, Knight A. The quality of life of people with epilepsy at a tertiary referral centre in Malaysia. Health and Quality of life Outcomes. 2013;11:143-48.

8. Shanmukhi S, Sita Jayalakshmi S, Anand B. Factors associated with quality of life in adult epilepsy patients-a hospital based study from south India. Res Neurol Int. 2015;1-5. 
9. Jacoby A. Epilepsy and the quality of everyday life: findings from a study of people with well-controlled epilepsy. Soc Sci Med. 1992;34:657-66.

10. Cramer JA, Perrine K, Devinsky O, Meador K. A brief questionnaire to screen for quality of life in epilepsy: the QOLIE-10. Epilepsia. 1996;37(6):577-82.

11. Suresh S, Chakraborty A, Virupakshaiah A, Kumar N. Efficacy and safety of levetiracetam and carbamazepine as monotherapy in partial seizures. epilepsy research and treatment. 2015:1-6.

12. Marson A, Al-Kharusi A, Alwaidh M, Appleton R, Baker G, Chadwick D, et al. The SANAD study of effectiveness of valproate, lamotrigine, or topiramate for generalised and unclassifiable epilepsy: an unblinded randomised controlled trial. Lancet. 2007;369(9566):1016-26.

13. Tatum WO IV, Benbadis S, Vale FL. The neurosurgical treatment of epilepsy. Arch Fam Med. 2000;9:1142-6.
14. Schmidt D. Efficacy of new antiepileptic drugs. Epilepsy Curr. 2011;11:9-11.

15. Ahmad N, Othaman NI, Islahudin F. Medication adherence and quality of life in epilepsy patients. Int $\mathrm{J}$ Pharm Pharm Sci. 2013;5(2):401-4.

16. Das K, Bannerjee M, Mondal GP, Devi LG, Singh OP, Mukherjee BB. Evaluation of socio-economic factors causing discontinuation of epilepsy treatment resulting in seizure recurrence: a study in urban epilepsy clinic. Seizure. 2007;16(7):601-07.

Cite this article as: Verma SK, Bala S, Singh Y, Kohli S, Kalra J, Dhasmana DC, et al. Evaluation of levetiracetam and valproic acid as monotherapy on quality of life in patients of generalized tonic clonic epilepsy. Int J Basic Clin Pharmacol 2018;7:669-75. 